\title{
Preliminary survey of the abundance of giant clams in Tun Sakaran Marine Park, Semporna, Sabah, Malaysia
}

\author{
Elvin Michael Bavoh*, Abd. Jalil Mapait and Mohd. Nara Ahmad \\ The Board of Trustees of Sabah Parks, P.O. Box 10626, 88806 Kota Kinabalu, Sabah, Malaysia \\ ${ }^{*}$ Corresponding author: embavoh@gmail.com
}

\begin{abstract}
Tun Sakaran Marine Park, TSMP, is home to endangered species of giant clams. However, there are few studies regarding the species-specific abundance of giant clams in the park. Thus, a preliminary survey was conducted from $17^{\text {th }}$ to $23^{\text {rd }}$ February 2014 to assess the abundance of giant clams (Tridacna squamosa, T. crocea, T. maxima, and Hippopus hippopus). Transect lines of $100 \mathrm{~m}$ were laid with the same depth contours of the reef (shallow reef $2-6 \mathrm{~m}$ depth), and giant clams found within the study area were identified and recorded. The results showed that the average abundance of giant clams is 7.17 individual $/ 100 \mathrm{~m}^{2}$. T. crocea has the highest abundance $\left(6.98\right.$ individual $\left./ 100 \mathrm{~m}^{2}\right)$, followed by T. maxima $(0.15$ individual $\left./ 100 \mathrm{~m}^{2}\right)$, T. squamosa $\left(0.02\right.$ individual $\left./ 100 \mathrm{~m}^{2}\right)$ and Hippopus hippopus $\left(0.02\right.$ individual $\left./ 100 \mathrm{~m}^{2}\right)$. Reefs of Sibuan, Mantabuan and Lagoon of Bodgaya-Bohey Dulang are believed to be an important habitat for T. crocea as most of these species were found there. However, further research covering deep reefs and intertidal areas over larger areas are required for generating comprehensive information.
\end{abstract}

Keywords: Giant clams, Tun Sakaran Marine Park, Population density, Conservation

\section{Introduction}

Tun Sakaran Marine Park (TSMP) is the 4th Marine Park of Sabah established in 2004 under the jurisdiction of The Board Trustees of Sabah Parks. TSMP is a unique marine park, where it allows local communities to live inside of the park. Communities from Bajau, Bajau Laut and Suluk inhabit islands such as Selakan, Sebangkat, Bodgaya. Some communities still live in small shelters built on water. TSMP is located at the heart of the Coral Triangle Initiative (CTI) area. It's home to 255 coral species and 528 reef fishes (Semporna Island Project, 2001). It's also a habitat for the endangered giant clam species.

There is some general information on abundance of giant clams in the TSMP but data on species composition and species-specific abundance is still lacking. The recent survey was done by Sabah Parks and Reef Check Malaysia during the annual survey of the reef status in the Park (Reef Check Malaysia, 2014). Thus, this preliminary study was conducted to determine the diversity and abundance of giant clams in TSMP.

\section{Materials and Methods}

\section{Study Site}

A survey was caried out at TSMP (latitude $4^{\circ} 33^{\prime} \mathrm{N}$ to $4^{\circ} 42^{\prime} \mathrm{N}$, and longitude $118^{\circ} 37^{\prime} \mathrm{E}$ to $118^{\circ} 51^{\prime} \mathrm{E}$ ) which has an area of $350 \mathrm{~km}^{2}$ in size (Semporna Island Project, 2001). The Survey was conducted on $17^{\text {th }}-23^{\text {rd }}$ February 2014. Survey sites were randomly selected within the park boundary. There were 22 survey sites in TSMP (Figure 1). Each transect covered around $500 \mathrm{~m}^{2}$ of area with total surveyed area of $11,000 \mathrm{~m}^{2}$.

\section{Method}

A $100 \mathrm{~m}$ calibrated fibreglass tape was laid underwater with the same depth contours of the reef (shallow reef 2 $6 \mathrm{~m}$ depth) by SCUBA diving at each of the survey sites. In shallow reef, snorkelling was sufficient to collect data whereas at much deeper water, SCUBA diving was carried out. The transects were divided into two sections which were at the right and left of the transect tape. Giant clams found $2.5 \mathrm{~m}$ to the right and left of transect line were counted and identified to the lowest taxonomic level as possible.

\section{Results and Discussion}

This survey managed to find only four species of giant clams, namely, Tridacna crocea, T. maxima, T. squamosa and Hippopus hippopus. Average abundance of giant clams at 22 survey sites was 7.17 individual $/ 100 \mathrm{~m}^{2}$ (Table 1 ). However, it differs from previous findings by Reef Check Malaysia in 2014, which reported that giant clam abundance at 14 survey sites in TSMP was 1.54 individual $/ 100 \mathrm{~m}^{2}$. Slight difference in abundance is due to larger area covered during this survey $\left(11,000 \mathrm{~m}^{2}\right)$ compared to the previous study $\left(5,600 \mathrm{~m}^{2}\right)$. It appeared that TSMP has the highest record of giant clam population compared to the others islands around Semporna waters. Previous study showed that the abundance of giant clams in 11 survey sites around the islands of Semporna was, with only 0.45 individual $/ 100 \mathrm{~m}^{2}$ (Reef Check Malaysia, 2014). Outside the marine park's boundary, giant clams are more susceptible to harvesting which resulted in their low abundance. 


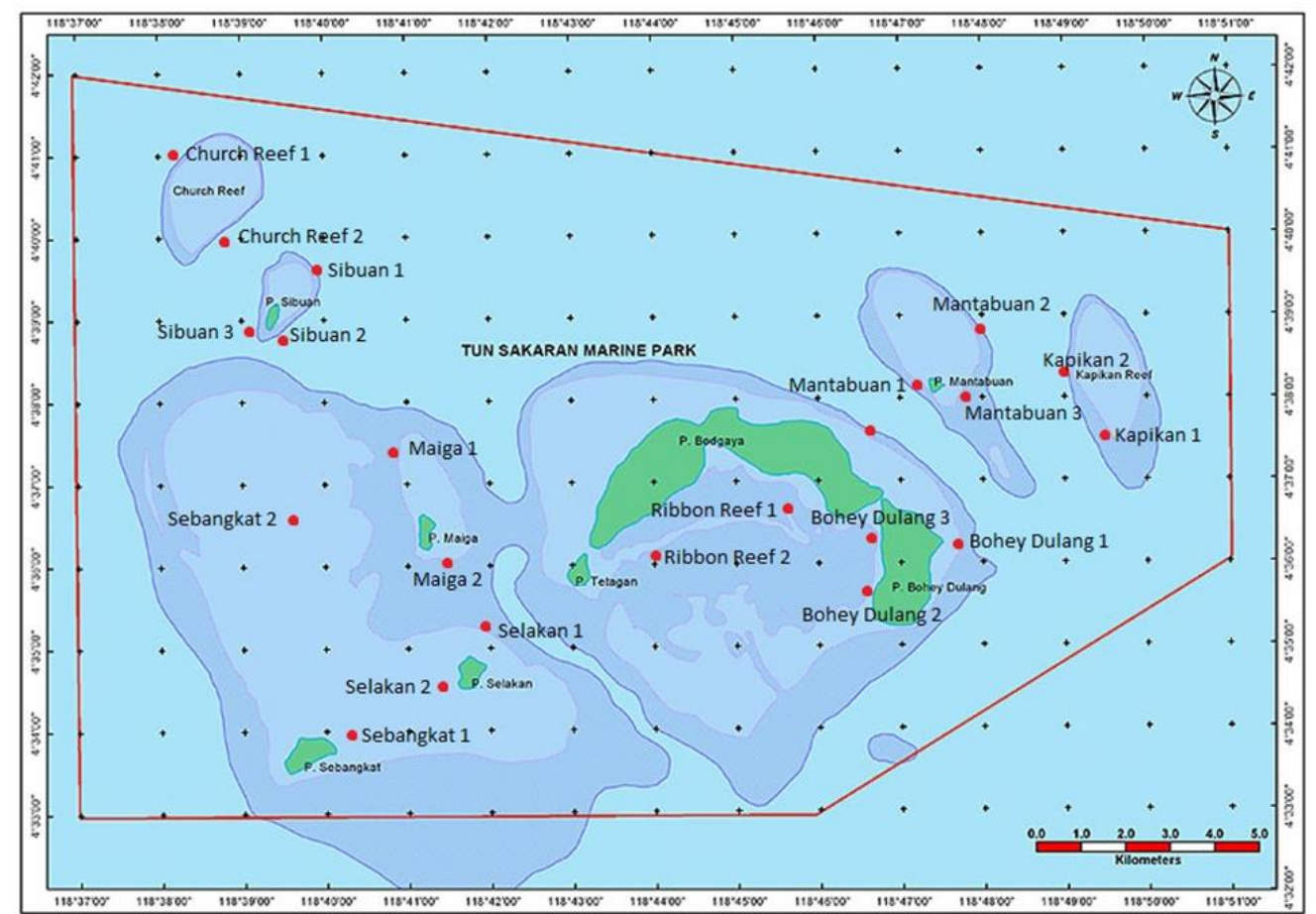

Figure 1. Survey sites in TSMP. (Map source: Semporna Island Project, 2004)

Table 1. Species composition and abundance of giant clams at different locations in 22 survey sites in TSMP. Note: the exact coordinates of the survey are not reported to avoid possible illegal harvesting.

\begin{tabular}{clccccc}
\hline & & \multicolumn{5}{c}{ Abundance (Individual/100m $\mathbf{2}^{\mathbf{2}}$. } \\
\hline Site no. & \multicolumn{1}{c}{ Site Name } & T. crocea & T. maxima & T. squamosa & H. hippopus & Total \\
\hline 1 & Church Reef 1 & 1.8 & 0 & 0 & 0 & 1.8 \\
2 & Church Reef 2 & 6.4 & 0 & 0 & 0 & 6.4 \\
$\mathbf{3}$ & Sibuan 1 & $\mathbf{2 0 . 0}$ & 0 & 0 & 0 & $\mathbf{2 0 . 0}$ \\
4 & Sibuan 2 & 19.0 & 0 & 0 & 0 & 19.0 \\
5 & Sibuan 3 & 9.8 & 0 & 0 & 0 & 9.8 \\
6 & Maiga 1 & 8.0 & 0.2 & 0 & 0 & 8.2 \\
7 & Maiga 2 & 0.6 & 0 & 0 & 0 & 0.6 \\
8 & Selakan 1 & 1.0 & 0 & 0 & 0 & 1.0 \\
9 & Selakan 2 & 0 & 0 & 0 & 0 & 0 \\
10 & Sebangkat 1 & 0 & 0 & 0 & 0 & 0 \\
11 & Sebangkat 1 & 1.0 & 0 & 0 & 0 & 1.0 \\
12 & Mantabuan 1 & 17.6 & 1 & 0 & 0 & 18.6 \\
13 & Mantabuan 2 & 0 & 0 & 0 & 0 & 0 \\
14 & Mantabuan 3 & 11.0 & 0.8 & 0 & 0 & 11.8 \\
15 & Kapikan 1 & 5.4 & 0.2 & 0 & 0 & 5.6 \\
16 & Kapikan 2 & 5.0 & 0.8 & 0 & 0 & 5.8 \\
17 & Bohey Dulang 1 & 1.4 & 0 & 0 & 0 & 1.4 \\
18 & Bohey Dulang 2 & 10.4 & 0 & 0.2 & 0.2 & 10.8 \\
19 & Bohey Dulang 3 & 6.2 & 0 & 0 & 0 & 6.2 \\
20 & Ribbon Reef 1 & 13.4 & 0.2 & 0 & 0 & 13.6 \\
21 & Ribbon Reef 2 & 10.4 & 0 & 0 & 0 & 10.4 \\
22 & Bodgaya & 5.2 & 0.2 & 0.2 & 0.2 & 5.8 \\
\hline & Average & 6.98 & 0.15 & 0.02 & 0.02 & 7.17 \\
\hline
\end{tabular}


Giant clam with highest abundance is T. crocea (6.98 individual $/ 100 \mathrm{~m}^{2}$ ) follow by $T$. maxima $(0.15$ individual $\left./ 100 \mathrm{~m}^{2}\right)$, T. squamosa $\left(0.02\right.$ individual $\left./ 100 \mathrm{~m}^{2}\right)$ and Hippopus hippopus (0.02 individual/100m²) (Table 1). Approximately $97 \%$ of giant clams' population in 22 survey sites was mainly $T$. crocea. Almost in all the study sites, $T$. crocea was encountered. The finding indicated that T. crocea still has a good population in TSMP. This is supported by other observations which indicated that only T. crocea has a stable population in Malaysia (Shauhwai and Yasin, 2003). One of the reasons could be that $T$. crocea has capability to burrow both by mechanical and chemical process which were described by Neo et al. (2014). Chemical etching is done by extending the pedal mantle tissue out of the byssal opening and the excreted solvents dissolve the substrate under and around the clam (Fatherree, 2006). Most of T. crocea was concentrated at Sibuan reefs, Mantabuan, and Lagoon of Bodgaya-Bohey Dulang Island which suggests that this area is an important habitat for this particular species, thus need continuous protection.

However, this study was only limited to shallow reefs (2-6m depth) in TSMP. Deep reefs (more than 6 meter) and intertidal zones were not observed. Lagoon of Bodgaya - Bohey Dulang island was thoroughly surveyed, especially the areas with reefs near the shore of both these islands. Further research is needed to cover more area in order to get better data in determining the stock of giant clams.

\section{Conclusion}

The average abundance of giant clams in TSMP is high compared to that outside this park, with T. crocea as the dominant species. Reefs of Sibuan, Mantabuan and Lagoon of Bodgaya-Bohey Dulang Island are believed to be important habitats for T. crocea. However, further research is needed to determine the the abundance of the clams over larger a larger arwa of TSMP.

\section{Acknowledgements}

Thanks are due to the management of Sabah Parks, especially Rimi Repin and Nasrulhakim Maidin for the support, guidance and encouragement provided for this study. We also acknowledge all our colleagues of Sabah Parks who helped in terms of logistics and other assistance.

\section{References}

Fatherree, J.W., 2006. Giant Clams in the Sea and the Aquarium: The biology, Identification, and Aquarium Husbandry of Tridacnid clams. Liquid Medium Publications. Favreau, J.M., Drew.

Neo M. L., Eckman, W, Vicentuan, K., Teo S. L. M., Todd, P. A., 2014. The ecological significance of giant clams in coral reef ecosystems. J. Biology Conservation 181, 111-123pp
Reef Check Malaysia. (2014). Status of Coral Reefs in Malaysia, 2014. Annual Report. 66. http://www.reefcheck.org.my/mediainformation/annual-survey-reports

Semporna Island Project. (2001). Management Plan for the Semporna Island Park, Sabah, Malaysia. Marine Conservation Society and Sabah Parks.

Shau-hwai, A. T., \& Yasin, Z. (2003). Status of giant clams in Malaysia. SPC Trochus Information Bulletin \#10, December, 9-10. 